\title{
GONADOTROPIC HORMONE: URINE ASSAYS OF NORMALLY CYCLING, MENOPAUSAL, CASTRATED, AND ESTRIN TREATED HUMAN FEMALES ${ }^{1}$
}

\author{
By CARL G. HELLER AND EMILY J. HELLER \\ (From the Department of Medicine, University of Wisconsin Medical School, Madison)
}

(Received for publication October 11, 1938)

Despite the numerous reports on the hormone content of human blood and urine, only a hazy concept of the actual and relative content of gonadotropic substance in urine or blood exists. As recently as June 10, 1937 the consensus at the meeting of the Section on Obstetrics, Gynecology, and Abdominal Surgery, at the EightyEighth Annual Session of the American Medical Association seemed to be that, although the hormone assays were of scientific interest, they had little clinical value as yet. To quote two opinions concerning hormone assays, Emil Novak said, "The papers we have heard today illustrate the usual inadequacy of blood and urine hormone studies in pointing the way toward successful treatment." (1); and Elmer Sevringhaus said, "These studies are still to be reserved for the highly experimental clinics, because assay technics are far from being uniformly reliable." (2).

The three most important underlying difficulties with the gonadotropic assays to date appear to be: (1), lack of adequate assay methods; (2), lack of reliable concentration methods; and (3), lack of a thorough knowledge of the normal physiology of gonadotropic hormones in the human being.

The assay methods have recently been improved by the introduction of reliable technics using the immature mouse (3) and the immature rat (4). The problem of urine concentration has also been simplified recently by Levin and Tyndale (5) who introduced the tannic acid method, and by Heller and Heller (6) who have successfully applied Zondek's alcohol-ether concentration method. This paper attempts to add information concerning the third problem, namely, the excretion rate

1 This research was supported by a Special Grant from the Wisconsin Alumni Research Foundation and a Research Fellowship provided by the Schering Corporation, both administered by Dr. E. L. Sevringhaus, and assisted in part by the University of Wisconsin WPA Natural Science Project. of the gonadotropic hormone of women during and after the menopause.

The specific questions we have tried to shed light on are:

(a) Is there any relationship between age and gonadotropic hormone titer?

(b) Is there a constant relationship between gonadotropic excretion of menopausal women who have symptoms and of those who do not?

(c) Is the gonadotropic content of urine reduced after the menopause is passed?

(d) Do surgical or radiation castrates differ from menopausal women in their gonadotropic excretion; is the amount of time elapsed since castration important?

(e) What is the urinary gonadotropic excretion of patients with involutional psychoses?

$(f)$ What is the urinary gonadotropic excretion of patients who have been hysterectomized?

$(g)$ What is the urinary gonadotropic excretion of normally cycling women of menopausal age?

(h) How rapid and how great is the change from the cycling condition to the menopausal condition?

However, before these questions are answered, it is necessary to present more specific information about the excretion of gonadotropic hormones by normal menopausal women. The following facts will be discussed; the extent of the normal daily variation in excretion; how dilution, concentration, and time of voiding (that is, night or day specimens) vary the assays; and whether women still exhibit cycles of excretion after the climacteric.

\section{MATERIALS AND METHODS}

In most instances, the patients were hospitalized cases ; in no instance was there any obvious metabolic disturbance other than the menopause. syndrome. Urine collections were made on both a 12-hour (overnight) and a 24-hour 
basis. The urine was placed in an ice chest immediately upon voiding; no preservatives were used. An aliquot sample of the total 12 or 24-hour specimen was precipitated. The final eluted material was so divided as to represent a specific fraction of the original volume, this fraction is referred to as the "equivalent dose." The concentration method has been previously described (6). The rats were slightly older than in previous reports $(4,6), 24$-day-old rats being used because of their better tolerance for the concentrates. Graded equivalents of the original urine were injected in 0.5 or $1.0 \mathrm{cc}$. doses 2 times per day for 3 days; autopsies were performed on the fourth day. Since from 1 to 10 rats were injected with different equivalent doses, a theoretically complete curve of response to dose was determined for each specimen of each patient. From this curve the minimal volume of urine necessary to produce a minimal uterine stimulation was approximated. The ratio between doses causing minimal uterine weight changes and doses causing minimal ovarian, weight changes was roughly one to two. In most cases, minimal stimulation was roughly calculated from the observed response to known equivalents. This is illustrated by a typical case (Table I) where 6 rats were used on 4 different dose levels. The conclusion in this case was that the minimal stimulating dose must lie between $25 \mathrm{cc}$. and $12.5 \mathrm{cc}$. equivalents, since the response was quite positive at 25 cc. and completely negative at 12.5 cc. A working unit of 18 was therefore adopted. It is recognized that this is a rough estimate, and that it could be improved by using more animals and more dose levels. However, it
TABLE I

Illustrating the results of gonadotropic assays on a single urine specimen

Name ST Date April 22, 1938 24-Hour Collection TOtAl VoluMe: $1340 \mathrm{cc}$. AliQUOTS: $500 \mathrm{cc}$.

Methods of PREcipitation: Alcohol-ether

Date of Precipitation: A pril 24

Date of InJECTION: April 26 Age of Rats: 24 days

\begin{tabular}{c|c|c|c|c}
\hline \hline Dose* & $\begin{array}{c}\text { Amount } \\
\text { injected }\end{array}$ & $\begin{array}{c}\text { Uterine } \\
\text { weight } \\
\text { +fluid }\end{array}$ & $\begin{array}{c}\text { Uterine } \\
\text { weight } \\
\text { - fluid }\end{array}$ & $\begin{array}{c}\text { Ovarian } \\
\text { weight }\end{array}$ \\
\hline & $c c$. & $m g m$. & $m g m$. & $m g m$. \\
100 & 1.0 & 225 & 110 & 80 \\
50 & 0.5 & 213 & 84 & 57 \\
50 & 0.5 & 260 & 101 & 35 \\
25 & 0.5 & 208 & 105 & 30 \\
25 & 0.5 & 190 & 84 & 36 \\
12.5 & 0.5 & & 22 & 11.2
\end{tabular}

* Volume of urine from which material injected was derived.

has proved to be a serviceable estimate for making comparisons.

The maximal daily variation in gonadotropic excretion was determined for several patients during long periods under the most varied conditions. Figure 1 illustrates the results from a patient aged 71 years. This case was chosen to illustrate daily variations because, first, it shows the most extreme variations ever seen in this laboratory and second, it was observed the longest, a little over 3 months. The following variation in con-

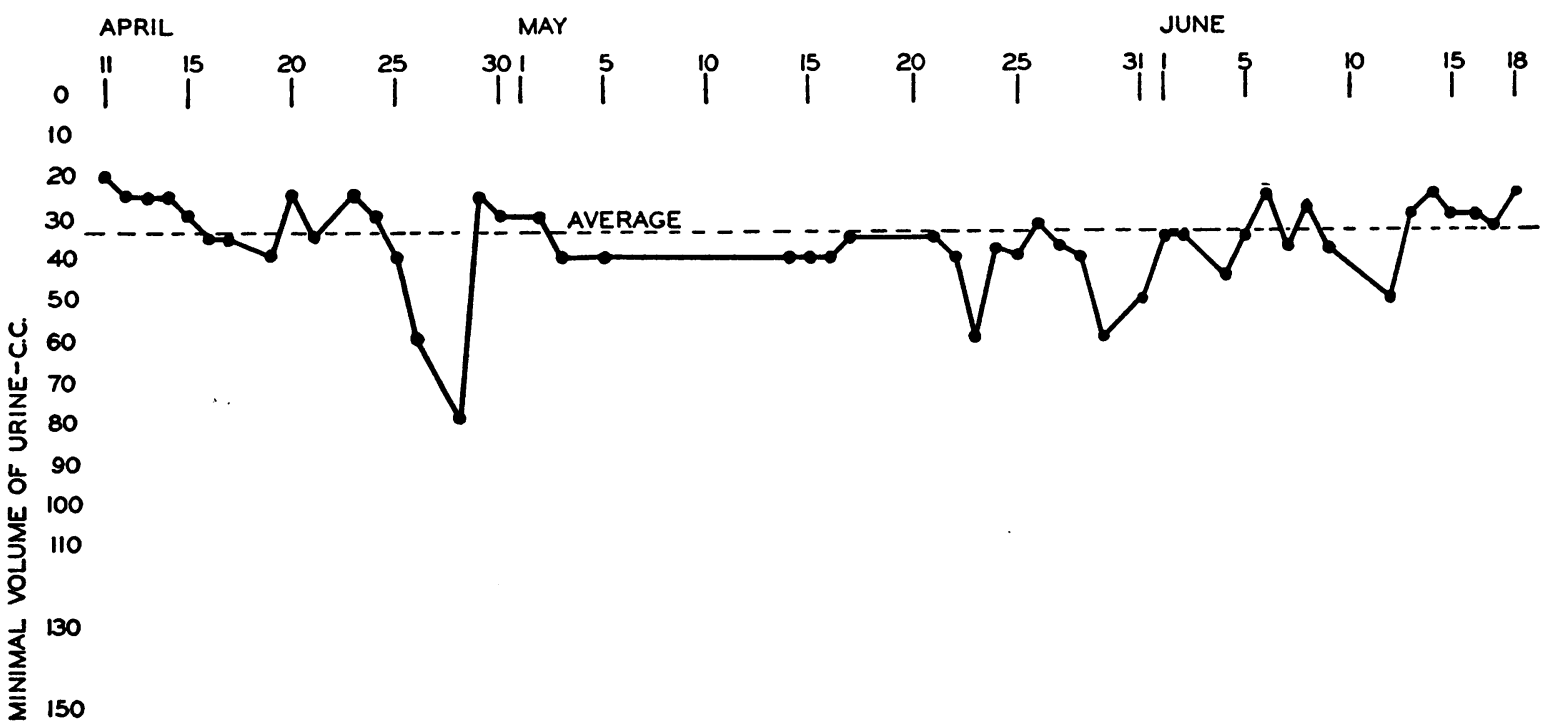

170

Fig. 1. Daily Variation in Gonadotropic Hormone Output for a 71-Year-Old Postmenopausal Woman

The minimal volume of urine-cc. indicates the least amount of urine that had to be concentrated in order to stimulate uterine development in the rat. 
ditions should be noted: (1), A complete 24-hour urine specimen was not always secured; (2), Refrigeration was omitted occasionally; (3), Length of time between urine collection and precipitation varied from 1 day to 6 weeks -without any preservative, but with refrigeration; (4), Length of time between precipitation and preparation of solution varied from 1 day to 2 months; (5), Length of time between preparation of solutions and injection varied from 1 to 10 days; (6), Responses of immature rats used are inherently variable; to this natural variation can be added the factors of toxicity of some specimens and not of others, subcutaneous hematomas causing occasional leakage; and finally, the variation in laboratory skill attending the concentrating of the urine. From Figure 1 it can be seen that the average response was at $34.8 \mathrm{cc}$. equivalents, the minimal response at $20 \mathrm{cc}$. equivalents, and the maximal response at $80 \mathrm{cc}$. equivalents. In percentages the most extreme variation from the mean response over the 3-month period was 43 per cent in the case of the minimal and 130 per cent in the case of the maximal.

The low assays were more probably due to any or all of the above mentioned variations than the high assays. The only condition that might cause a false high assay is an incomplete specimen that contains the highly concentrated night urine. Therefore, in a practical interpretation of an individual result, more faith may be put in the higher assays.

In the above case no corrections were made for variations in volume (which were substantial) because of the known incompleteness of the collections. When and if completeness of collection is secured, a correlation can be found between volume and response. In general, it was observed that the response per unit volume varied inversely with the volume itself.

A study of the day-to-day variations, which in all other cases were smaller than those in the case discussed above, indicates that not more than 3 samples collected on consecutive days are needed to furnish a satisfactory estimate of gonadotropic hormone content of the urine from a given patient. To date, no indication of any cyclic variations in excretory activity during or after the menopause has been noted. Twelve-hour night specimens offer the advantage of originally supplying the gonadotropic hormone in a more concentrated form than the 24-hour specimens. They were therefore adopted for routine collections.

\section{RESULTS AND DISCUSSION}

Urines from 66 patients were concentrated and assayed as described. The ages of the patients ranged from 24 to 77 years.

From Figure 2 it can be seen that, when classed according to titer, the patients fall into three general classes. (1) Those whose urines showed very low gonadotropic potency were all from patients exhibiting regular normal cycles. Those whose urines ran the whole gamut of titers from the lowest to the highest were from women having irregular cycles. (3) Those whose urines were very high in potency were from women who have ceased cycling, either spontaneously or artificially. The minimal volume of urine necessary to stimulate one rat was, for each of the three groups, 400 to $500 \mathrm{cc}$., 25 to $400 \mathrm{cc}$., and 10 to 30 cc., respectively.

It was observed that women having regular normal menstrual cycles excrete varying amounts of gonadotropic hormone during their cycle. However, there is no day in the cycle when gonadotropic hormone is regularly absent from the urine, as is so frequently claimed. Usually there is a rise in titer between the 10th and 20th days. Therefore assaying urine during the mid-interval was avoided when comparisons were being made between the potency of normal and menopausal women.

The assays answer the questions originally posed in the following manner:

(a). Concerning the relationship of age to gonadotropic potency a brief inspection of Table II shows that age is a factor only insofar as it influences the time of onset of the menopause. Women who have not yet reached the climacteric excrete little gonadotropic material, regardless of age. Women who have passed the climacteric have a high urinary gonadotropic output. This point can be illustrated by noticing that Patient Sf, Class 6, a premature menopausal case, had a high concentration at age 25 years, while an older non-menopausal patient, $\mathrm{Be}$, Class 1 , was still low in potency at age 48 .

(b). Symptoms did not influence gonadotropic potency. "Symptoms" when used in this report will refer to both the autonomic and psychic symptoms of the menopause as described by Sevringhaus (7). Patients with symptoms who have ceased cycling, Class 6 , have high titers. Patients without symptoms who have ceased cycling, Class 5 , have titers just as high. The series of 14 castrates (Classes 7 and 8 ) further substantiates the lack of correlation between symptoms and gonadotropic excretion. All 14 were almost exactly alike in potency, although 10 had vasomotor symptoms and the other 4 had none. Those women who cycle regularly (Classes 1 and 2) and those cycling irregularly (Classes 3 and 4) 
TABLE II $\ddagger$

Gonadotropic hormone titer of women in the menopausal age period

\begin{tabular}{|c|c|c|c|c|}
\hline \multirow[b]{2}{*}{ Class } & \multicolumn{2}{|l|}{ Cycling regularly } & \multicolumn{2}{|r|}{ Cycling irregularly } \\
\hline & $\stackrel{1}{1}$ & $\underset{\text { symptoms }}{\stackrel{2}{\text { Having }}}$ & $\begin{array}{c}3 \\
\text { No } \\
\text { symp- } \\
\text { toms }\end{array}$ & $\begin{array}{c}4 \\
\text { Having symptoms }\end{array}$ \\
\hline 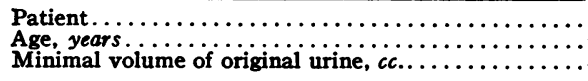 & $\begin{array}{|rrrrrrr|}\mathrm{Mu} & \mathrm{Wa} & \mathrm{Ol} & \mathrm{Ov} & \mathrm{Be} & \mathrm{Ca} & \mathrm{Gu} \\
43 & 44 & 33 & 47 & 48 & 45 & 43 \\
400 & 400 & 500 & 400 & 400 & >300 & 400\end{array}$ & \begin{tabular}{|rrr}
$S_{w}$ & $E r$ & $+B y$ \\
52 & 45 & 44 \\
$>100$ & 400 & 400
\end{tabular} & $\begin{array}{l}\text { Gi } \\
45 \\
30\end{array}$ & $\begin{array}{rlllllll}\dagger \mathrm{Tu} & \mathrm{La} & \mathrm{Po} & \mathrm{Ne} & \mathrm{Kr} & \mathrm{He} & \mathrm{Br} & +\mathrm{Bn} \\
42 & 42 & 36 & 46 & 38 & 45 & 46 & 49 \\
400 & 60 & 25 & 50 & 50 & 100 & 25 & 80\end{array}$ \\
\hline
\end{tabular}

\begin{tabular}{|c|c|c|}
\hline \multirow{2}{*}{ Class } & \multicolumn{2}{|c|}{ Not cycling } \\
\hline & $\stackrel{5}{\text { No symptoms }}$ & Having 8ymptoms \\
\hline 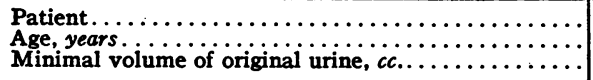 & 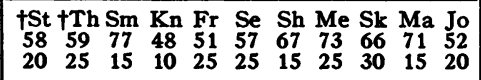 & 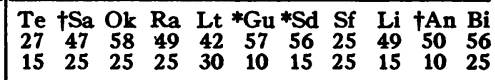 \\
\hline
\end{tabular}

\begin{tabular}{|c|c|c|c|}
\hline & \multicolumn{2}{|r|}{ Castrate } & \multirow{2}{*}{$\begin{array}{c}\text { Hysterectomized } \\
\stackrel{9}{\text { Having symptoms }}\end{array}$} \\
\hline & $\stackrel{7}{7}$ & $\begin{array}{c}8 \\
\text { Having symptoms }\end{array}$ & \\
\hline 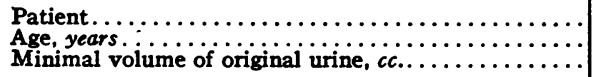 & $\begin{array}{|cccc|}\mathrm{Le} & \mathrm{Ba} & +\mathrm{S} 1+\mathrm{Ko} \\
52 & 47 & 47 & 24 \\
25 & 20 & 15 & 20\end{array}$ & \begin{tabular}{|cccccccccc}
$+\mathrm{fe}$ & $+\mathrm{Zu}$ & $+\mathrm{Vi}$ & $\mathrm{Gl}$ & $+\mathrm{Fh}$ & $\mathrm{Lg}$ & $\mathrm{Sr}$ & $\mathrm{Bl}$ & $+\mathrm{Da}$ & $\mathrm{Sc}$ \\
47 & 43 & 33 & 40 & 29 & 39 & 36 & 46 & 29 & 43 \\
15 & 25 & 20 & 15 & 10 & 25 & 20 & 25 & 30 & 40
\end{tabular} \mid & $\begin{array}{lrrrrr}\text { Lh } & \text { Ve } & \text { Ho } & \text { Gu } & \text { Sd } & \text { Ht } \\
46 & 36 & 43 & 57 & 56 & 48 \\
25 & >200 & 40 & 10 & 15 & 25\end{array}$ \\
\hline
\end{tabular}

\begin{tabular}{|c|c|c|c|c|c|c|c|c|c|c|c|c|c|c|c|c|}
\hline & \multicolumn{16}{|c|}{ Involution } \\
\hline Class & \multicolumn{16}{|c|}{10} \\
\hline 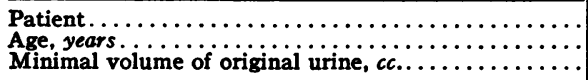 & $\begin{array}{l}\mathrm{Je} \\
47 \\
15\end{array}$ & $\begin{array}{r}\mathrm{Lr} \\
48 \\
200\end{array}$ & $\begin{array}{r}\text { At } \\
39 \\
275\end{array}$ & $\begin{array}{l}\text { Fh } \\
29 \\
10\end{array}$ & $\begin{array}{l}\text { An } \\
50 \\
10\end{array}$ & $\begin{array}{l}\text { St } \\
\mathbf{5 8} \\
20\end{array}$ & $\begin{array}{c}\text { Th } \\
59 \\
25\end{array}$ & $\begin{array}{r}\text { Tu } \\
42 \\
400\end{array}$ & $\begin{array}{l}\mathrm{Vi} \\
33 \\
25\end{array}$ & $\begin{array}{c}\mathrm{Ve} \\
36 \\
>200\end{array}$ & $\begin{array}{l}\text { S1 } \\
47 \\
15\end{array}$ & $\begin{array}{c}\text { Ko } \\
24 \\
20\end{array}$ & $\begin{array}{l}\mathrm{Da} \\
29 \\
30\end{array}$ & $\begin{array}{l}Z u \\
43 \\
25\end{array}$ & $\begin{array}{l}\text { Bn } \\
49 \\
80\end{array}$ & $\begin{array}{r}\text { By } \\
44 \\
400\end{array}$ \\
\hline
\end{tabular}

\begin{tabular}{|c|c|c|c|c|c|c|c|c|c|c|c|c|c|c|c|}
\hline \multirow{3}{*}{ 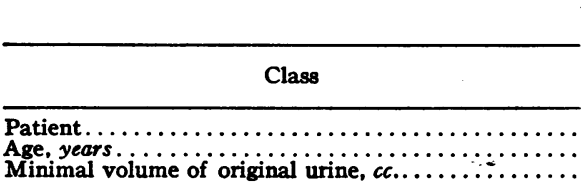 } & \multicolumn{15}{|c|}{ Estrin treated cases } \\
\hline & \multicolumn{15}{|c|}{$\begin{array}{c}11 \\
\text { Showing improvement of symptoms }\end{array}$} \\
\hline & $\begin{array}{l}\mathrm{Ls} \\
31 \\
40\end{array}$ & $\begin{array}{c}\mathrm{Kn} \\
48 \\
10\end{array}$ & $\begin{array}{l}\mathrm{Sr} \\
36 \\
25\end{array}$ & $\begin{array}{l}\mathrm{Lg} \\
39 \\
25\end{array}$ & $\begin{array}{l}\mathrm{Sa} \\
47 \\
25\end{array}$ & $\begin{array}{l}\mathrm{Vi} \\
33 \\
.50\end{array}$ & $\begin{array}{l}\mathrm{Bi} \\
56 \\
40\end{array}$ & $\begin{array}{l}\mathrm{E} 1 \\
42 \\
30\end{array}$ & $\begin{array}{l}\text { Sd } \\
56 \\
20\end{array}$ & $\begin{array}{l}\text { Ac } \\
49 \\
40\end{array}$ & $\begin{array}{l}\text { Fh } \\
29 \\
20\end{array}$ & $\begin{array}{l}\mathrm{Pa} \\
52 \\
10\end{array}$ & $\begin{array}{l}\text { Fh } \\
29 \\
20\end{array}$ & $\begin{array}{l}\mathrm{Li} \\
\mathbf{4 9} \\
10\end{array}$ & $\begin{array}{c}\text { Bk } \\
51 \\
30\end{array}$ \\
\hline
\end{tabular}

¥ Symptoms-Refers to the presence or absence of vasomotor phenomena at the time of titration.

* Also classed as Hysterectomy.

+ Also classed as Involution.

$>$ indicates a negative reaction with the volume of urine used.

tend to further the same argument, that there is no correlation between presence or absence of symptoms and gonadotropic titer. Similarly, there is no correlation between severity of symptoms and gonadotropic potency. For example, Patient $\mathrm{Ba}$, Class 7 , who had no symptoms, $\mathrm{Pa}-$ tient $\mathrm{Sr}$, Class 8 , who had unusually severe symptoms, and Patient $\mathrm{Bl}$, Class 8 , who had mild symptoms all had the same gonadotropic concentration.

(c). Many clinicians still retain the belief that at the menopause there is a greater gonadotropic excretion than at any other time, although Österreicher (8), Saethre (9), and Jones and MacGregor (10) have already pointed out that senile women have a high gonadotropic excretion. Saethre (11) differs with Zondek (12), who reported negative findings in 85 per cent of postmenopausal women investigated. Classes 5 and 7 substantiate the observation that once the gonadotropic concentration rises at the time of the climacteric, it remains at the same high level throughout the duration of life. Neither the presence or 
absence of symptoms at the time of the climacteric, nor the length of time elapsed since the climacteric seem to influence the gonadotropic excretion rate.

$(d)$. There is no essential difference between the gonadotropic potency of urines from spontaneous and artificial menopause patients (see Classes 5, 6, 7, and 8 in Table II and Figure 2). The length of time elapsed since castration does not play an important rôle either; for example, Patient Le who had been a castrate for 20 years, and Patient $\mathrm{Ba}$ who had been castrated only 6 months before, had the same potency (Class 7).

(e). There was no uniformity in gonadotropic assay in urines from patients diagnosed as having involutional psychoses. But when these cases were reclassified according to the regularity, irregularity, or cessation of their menstrual cycles, their titers fitted in with those of the groups with which they were classed (see Class 10 and those marked $\dagger$ in the other classes).

$(f)$. The hysterectomized patients (Class 9), had nothing in common with one another, but seemed to titrate high or low according to whether or not they fell into the true menopause class. Since there could be no evidence of cyclic activity any reclassification is only a guess.

$(g)$. The status of the menstrual cycle, i.e., regular, irregular, or absent, is the only factor which influences the urinary gonadotropic potency during the menopausal period. Classes 1 and 2, consisting of regularly cycling women with uneventful menstrual histories, contained uniformly low titers. From 400 to $500 \mathrm{cc}$. of urine was necessary to stimulate one rat. Classes 5, 6, 7, and 8 , consisting of acyclic women of menopausal age or beyond, contain uniformly high titers, 10 to $30 \mathrm{cc}$. being needed to stimulate one rat.

Between these two extremes lie Classes 3 and 4. These women all gave a history of having had regular cycles until recently, now they have become irregular in one way or another, i.e., in time, duration of flow, amount of flow, etc. The most common changes observed were: lengthening of the cycle, skipping periods, and scantier flow. All but one were having mild or severe vasomotor symptoms. However, the majority had had symptoms and irregularities of the cycle for but a short time. Thus these women may be considered to be just entering the menopause, or in a transitional period between normal cycles and the menopausal state. As is to be expected, the gonadotropic titers were in general neither as high as in the menopausal state or as low as in the normal state. However, titers equal to either of the other two classifications were encountered.

Thus, while there is a lack of correlation between gonadotropic titer and age, symptoms, hysterectomy, and involution, there is a definite correlation between gonadotropic hormone titer and the presence or absence of the menstrual cycle in women of menopausal age.

(h). A striking observation about these assays is the tremendous difference between urines of normal and menopausal women. A 20-fold increase in gonadotropic potency occurs at the time of the climacteric. This increase develops in a relatively short time, probably 2 to 10 years. In order to definitely establish this, individual cases should be followed through the menopausal period.

One of the practical applications of these findings is that premature menopause can be differentiated from the other amenorrheas. Two cases of amenorrhea in young women, Sf, in Class 6, aged 25, and another patient aged 25, were recently studied. Patient Sf titrated high (25 cc.) and was classed as a premature menopause, while the other case proved to be completely negative in gonadotropic content at the $800 \mathrm{cc}$. level. This response is less than occurs in the normal, since urine from normal women elicits positive responses at the 400 to $500 \mathrm{cc}$. level. These findings confirm the clinical diagnoses of premature menopause and hypopituitary amenorrhea, respectively.

Another practical clinical application, and perhaps the one of greatest importance, would be the use of the gonadotropic titer as a therapeutic index in treating menopausal symptoms with the estrogens. Albright (13), Frank and Salmon (14), Jones, MacGregor, and Tod (15), and others have reported decreases of gonadotropic excretion which occurred concurrently with the clinical improvement of the menopausal symptoms. Jones, MacGregor, and Tod (15) found that certain refractory psychotic postmenopausal cases showed a reduction in gonadotropic potency, although they did not respond to estrogen therapy clinically.

We were therefore disappointed to find that 


\section{MINIMAL VOLUME OF URINE-C.C.}
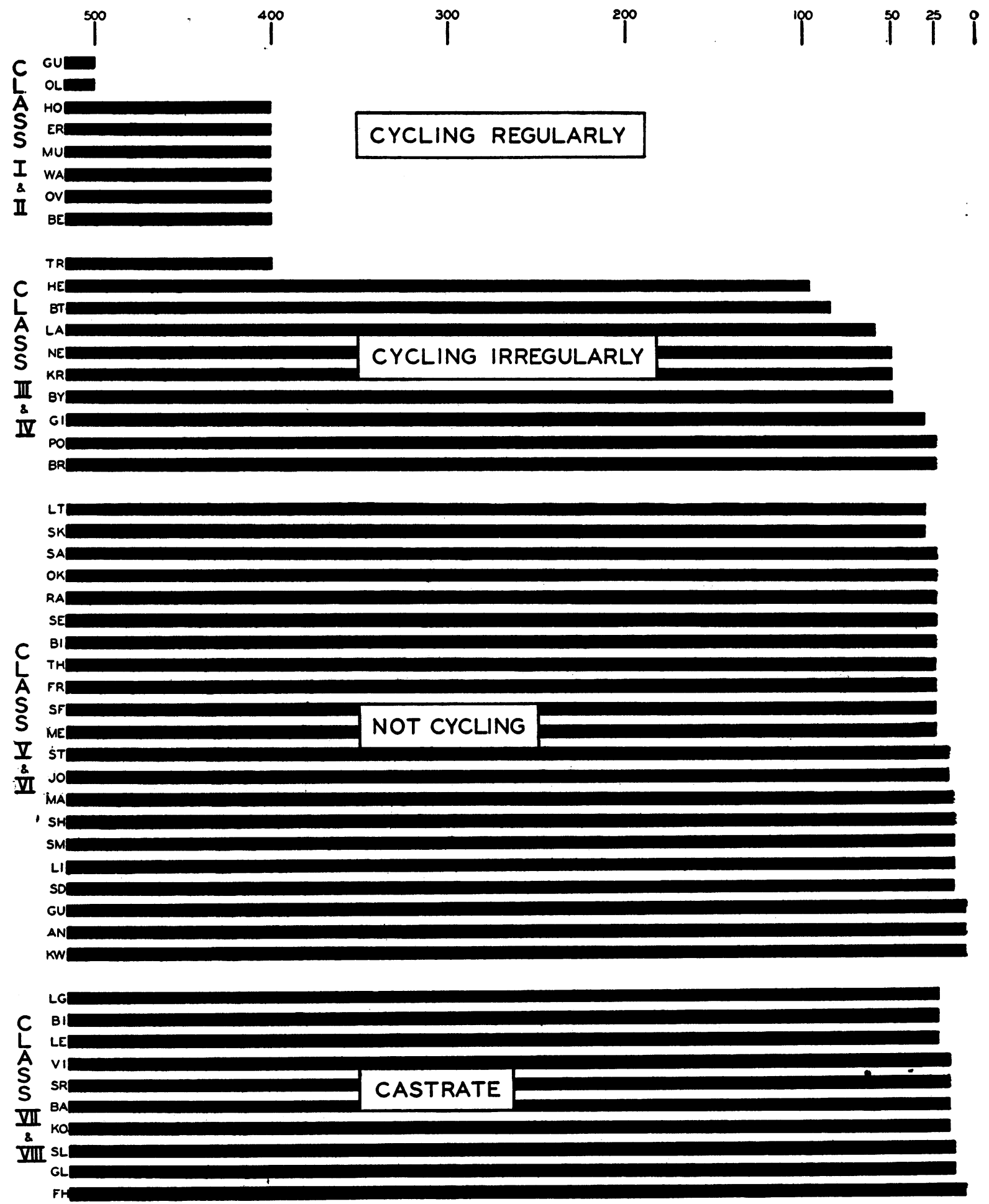

Fig. 2. The Gonadotropic Hormone Excretion of Menopausal Women

The minimal volume of urine-cc. indicates the least amount of urine that had to be concentrated in order to stimulate uterine development in the rat. 
estrogen treatment ${ }^{2}$ did not materially reduce gonadotropic potency (Class 11) in the 15 cases which we have discussed. In each instance estrogen therapy caused a definite clinical improvement. The amounts and methods of administration varied with the individual patient. Two preparations were used-Amniotin (Squibb) and Progynon DH (Schering). Amniotin, 2000 I.U., given orally four times a day was the usual maximum dose. In two refractory cases, intramuscular injection of 10,000 I.U. daily was resorted to. Usually clinical relief was achieved in less than one month. Samples for assay were taken from one month to one year after therapy was instituted, and while it was continued.

The number of cases is small and the time of treatment is relatively short. When estrogenic therapy was continued for longer periods, the gonadotropic potency was reduced to a 40 to 50 cc. minimal in a few cases. This is still far from the normal minimal of 400 to $500 \mathrm{cc}$.

The reports by earlier workers may be rationalized if one considers that only positive or negative stimulation of the assay animals was observed. An analysis of their data shows that their assays were probably made at the borderline of minimal stimulation. Therefore any slight change in potency might account for the negative findings reported in treated cases. Since these workers do not mention the gonadotropic titer of normally cycling asymptomatic women, or of acyclic asymptomatic menopausal women in the same age groups as patients with symptoms, undue significance possibly may have been attached to a very slight decrease in gonadotropic potency.

From our results, it would seem that gonadotropic hormone is not the chief factor concerned with the symptoms of the menopause, as Albright (13) and others suggested it might be. In proof of this we have offered the evidence; (1), that the titer of symptomless women can not be distinguished from those having symptoms; (2) that estrin therapy, at a point that adequately controlled the symptoms, did not reduce the gonadotropic titer (although upon further treatment the

2 The estrogen treated patients were made available for this study through the kindly cooperation of Dr. E. L. Sevringhaus and Dr. E. S. Gordon of the Department of Medicine and of Dr. M. J. Musser of the Department of Neuropsychiatry. potency is sometimes slightly reduced); (3), the animal work recently reported by Lauson, Heller, and Sevringhaus (16). It was shown that estrogenic substitution, in doses which caused thymus atrophy, pituitary hypertrophy, and constant vaginal estrus did not materially reduce the pituitary potency of castrated female rats. Therefore, it is to be seriously questioned that estrogens can return the potency to normal without having the unfavorable or undesired side affects, which occur in castrated rats.

Henderson and Rowlands (17) have recently assayed pituitaries obtained at autopsy from women of various ages. They found that the pituitaries from premenopausal individuals were low in gonadotropic potency, that an abrupt rise occurred at the time of the menopause, and that the high potency was maintained during senility. We have assayed the serum from 10 of the cases reported here. Ten cc. were injected in 1 cc. doses twice daily for 5 days. All serum from women who had low urinary gonadotropic potency was negative. Most of the serum from women who had a high urinary potency gave a positive gonadotropic reaction. So there appears to be a positive correlation between the gonadotropic titers from the pituitary gland, the blood serum, and the urine in the human female.

\section{SUMMARY}

Urines from 66 menopausal patients were assayed for their gonadotropic potency. It was found that their potency was not related to the presence or absence of symptoms, age, hysterectomy, or the involution. No difference in gonadotropic potency was found between menopausal women with symptoms and senile women, castrated women or menopausal women without symptoms.

Urinary gonadotropic concentration was low in women with regular normal menstrual cycles, high in menopausal women in whom cycles had ceased, and intermediate in menopausal women with irregular cycles.

Estrogen treatment alleviated the vasomotor symptoms of 15 menopausal women but failed to concurrently reduce their gonadotropic potency. Continued estrogen therapy caused a slight reduction in potency, but failed to suppress it by significant amounts. 
We wish to express our appreciation for the diligent help given us by Arthur Bleecker and Lewis Aasen in making the assays.

\section{BIBLIOGRAPHY}

1. Novak, E., Discussion following papers read at the Section on Obstetrics, Gynecology, and Abdominal Surgery, at the Eighty-Eighth Annual Session of the American Medical Association. J. A. M. A., 1937, 109, 1877.

2. Sevringhaus, E. L., Ibid. J. A. M. A., 1937, 109, 1878.

3. Levin, L., and Tyndale, H. H., The quantitative assay of "follicle-stimulating" substances. Endocrinology, 1937, 21, 619.

4. Heller, C. G., Lauson, H., and Sevringhaus, E. L., The immature rat uterus as an assay end-point for gonadotropic substances. Am. J. Physiol., 1938, 121, 364.

5. Levin, L., and Tyndale, H. H., Concentration and purification of the gonadotropic substance in urine of ovariectomized and post-menopausal women. Proc. Soc. Exper. Biol. and Med., 1936, 34, 516.

6. Heller, C. G., and Heller, E. J., Gonadotropic hormone-clinical application of extraction methods for assay purposes. Endocrinology, 1939. (In press.)

7. Sevringhaus, E. L., The menopause: Diagnostic and therapeutic problems. Southwestern Med., 1938, $22,128$.
8. Osterreicher, W., Vermehrte Ausscheidung von $\mathrm{Hy}$ pophysenvorderlappenhormon (Prolan) im Harne in Der Involutionsperiode BZW. im Senium. Klin. Wchnschr., 1932, 11, 813.

9. Saethre, H., Titrierung von Sexualhormonen Bei Geisteskranken. Klin. Wchnschr., 1933, 12, 1409.

10. Jones, M. S., and MacGregor, T. N., Inhibitory effect of follicular hormone on the anterior pituitary in humans. Lancet, 1936, 2, 974.

11. Saethre, H., Uber die Ausscheidung von Prolan Im Harne In Der Involutionsperiode BZW. Im Senium. Klin. Wchnschr., 1933, 12, 1727.

12. Zondek, B., Die Hormone des Ovarium und des $\mathrm{Hy}-$ pophysenvorderlappens. Julius Springer, Berlin, 1931, 1st ed.

13. Albright, F., Studies on ovarian dysfunction. III. The menopause. Endocrinology, 1936, 20, 24.

14. Frank, R. T., and Salmon, U. J., Effect of administration of estrogenic factor upon hypophyseal hyperactivity in the menopause. Proc. Soc. Exper. Biol. and Med., 1935, 33, 311.

15. Jones, M. S., MacGregor, T. N., and Tod, H., Oestradiol benzoate therapy in depressions at the menopause. Lancet, 1937, 1, 320.

16. Lauson, H., Heller, C. G., and Sevringhaus, E. L., Inadequacies of estradiol substitution in ovariectomized albino rats. Endocrinology, 1938, 23, 479.

17. Henderson, W. R., and Rowlands, I. W., The gonadotropic activity of the anterior pituitary gland in relation to increased intracranial pressure. Brit. M. J., 1938, 1, 1094. 